\title{
Correlation between angiographic transit times and neurological status on admission in patients with aneurysmal subarachnoid hemorrhage
}

\author{
Alexander Ivanov, MD, ${ }^{1}$ Andreas Linninger, PhD, ${ }^{1,2}$ Chih-Yang Hsu, BS, ${ }^{2}$ \\ Sepideh Amin-Hanjani, MD, ${ }^{1}$ Victor A. Aletich, MD, ${ }^{1}$ Fady T. Charbel, MD, ${ }^{1}$ and Ali Alaraj, MD1 \\ Departments of ${ }^{1}$ Neurosurgery and ${ }^{2}$ Bioengineering, University of Illinois at Chicago, Illinois
}

\begin{abstract}
OBJECTIVE The use of digital subtraction angiography (DSA) for semiquantitative cerebral blood flow (CBF) assessment is a new technique. The aim of this study was to determine whether patients with aneurysmal subarachnoid hemorrhage (aSAH) with higher Hunt and Hess grades also had higher angiographic contrast transit times (TTs) than patients with lower grades.
\end{abstract}

METHODS A cohort of 30 patients with aSAH and 10 patients without aSAH was included. Relevant clinical information was collected. A method to measure DSA TTs by color-coding reconstructions from DSA contrast-intensity images was applied. Regions of interest (ROIs) were chosen over major cerebral vessels. The estimated TTs included time-to-peak from $0 \%$ to $100 \%$ ( $\left.\mathrm{TTP}_{0-100}\right)$, TTP from $25 \%$ to 100\% ( $\left.\mathrm{TTP}_{25-100}\right)$, and TT from 100\% to 10\% ( $\left.\mathrm{TT}_{100-10}\right)$ contrast intensities. Statistical analysis was used to compare TTs between Group A (Hunt and Hess Grade I-II), Group B (Hunt and Hess Grade III-IV), and the control group. The correlation coefficient was calculated between different ROIs in aSAH groups.

RESULTS There was no difference in demographic factors between Group $A(n=10)$, Group $B(n=20)$, and the control group $(n=10)$. There was a strong correlation in all TTs between ROIs in the middle cerebral artery $\left(M_{1}, M_{2}\right)$ and anterior cerebral artery $\left(A_{1}, A_{2}\right)$. There was a statistically significant difference between Groups $A$ and $B$ in all TT parameters for ROls. $\mathrm{TT}_{100-10}$ values in the control group were significantly lower than the values in Group B.

CONCLUSIONS The DSA TTS showed significant correlation with Hunt and Hess grades. TT delays appear to be independent of increased intracranial pressure and may be an indicator of decreased CBF in patients with a higher Hunt and Hess grade. This method may serve as an indirect technique to assess relative CBF in the angiography suite.

http://thejns.org/doi/abs/10.3171/2015.4.JNS15134

KEY WORDS digital subtraction angiography; transit times; subarachnoid hemorrhage; Hunt and Hess; neurological outcome; vascular disorders

A NEURYSMAL subarachnoid hemorrhage (aSAH) remains a devastating disease with significant morbidity and mortality. ${ }^{21,23}$ The morbidity of aSAH depends on multiple factors that affect the postictal cerebral metabolism status, ${ }^{16}$ with alteration in cerebral perfusion, intracranial pressure (ICP), and cerebral blood flow (CBF) ${ }^{6,11,22,36}$ There are several techniques for noninvasive assessment of CBF including CT angiography ${ }^{11,19}$ and quantitative MR angiography. . $^{1-3,9,13,33,35}$ New computational methods have been developed to evaluate cortical tran- sit times (TTs) ${ }^{15,28}$ However, not all of these methods are available in the angiography suite, and they often require additional radiation or contrast exposure. There are no prior studies that attempted to correlate the angiographic contrast TTs with the neurological exams of patients with aSAH.

In our current study, we sought to apply a computational method based on digital subtraction angiography (DSA) analysis to evaluate the relative CBF in patients with aSAH. This method does not require additional ra-

ABBREVIATIONS aSAH = aneurysmal subarachnoid hemorrhage; CBF = cerebral blood flow; DICOM = Digital Imaging and Communications in Medicine; DSA = digital subtraction angiography; EVD = external ventricular drain; GOS = Glasgow Outcome Scale; ICA = internal carotid artery; ICP = intracranial pressure; $\mathrm{mRS}=$ modified Rankin Scale; $\mathrm{ROI}=$ region of interest; TT = transit time; TTP = time-to-peak.

SUBMITTED January 19, 2015. ACCEPTED April 6, 2015.

INCLUDE WHEN CITING Published online October 9, 2015; DOI: 10.3171/2015.4.JNS15134. 
diation or contrast exposure and may be applied during angiography in real-time. This technique is based on the analysis of DSA contrast TTs in multiple regions of interest (ROIs), corresponding to the major components of the anterior intracranial circulation. We report the correlation of DSA contrast TTs in patients with aSAH in relation to the clinical presentation graded by the Hunt and Hess classification. ${ }^{20}$

\section{Methods \\ Patient Data}

Institutional review board approval was obtained prior to the initiation of the study. This is a retrospective study on prospectively collected data at a tertiary center. A cohort of 30 patients with aSAH and 10 recent consecutive patients without aSAH (control group) was included in the study period from November 2011-May 2013. The patients with aSAH were also part of a study that evaluated vasospasm treatment as they developed clinical vasospasm following hospital admission. Demographic variables, neurological status (Hunt and Hess grade) on admission, and medical comorbidities data were collected. To increase the prognostic power of our scale, patients with Hunt and Hess Grades I-II were defined as having mild aSAH (Group A), and patients with Hunt and Hess Grades III-V were considered to have severe aSAH (Group B). ${ }^{31,37}$ Outcomes were assessed at 6 months using the Glasgow Outcome Scale (GOS) and the modified Rankin Scale (mRS). Patients who underwent DSA within 24 hours of aneurysm rupture were included in this assessment. Patients who underwent angiography more than 24 hours after aSAH ictus, patients with non-aSAH (traumatic, angiogram negative), and those with angiographic vasospasm on presentation or associated with large hematomas were excluded from the study. Patients with hydrocephalus on admission or those with Hunt and Hess Grades III-V typically had an external ventricular drain (EVD) catheter inserted on admission prior to DSA. Only 3 patients in the cohort, all with Hunt and Hess Grade III, did not have EVDs inserted. All EVDs were opened to drain at $10 \mathrm{~mm} \mathrm{Hg}$ during angiography as part of our routine practice.

\section{Image Acquisition}

All angiography was performed using the standard transfemoral approach. A 5F diagnostic catheter (Angiodynamics) was inserted into the internal cerebral arteries, and $12 \mathrm{ml}$ of the iodine-based contrast agent iohexol (300 $\mathrm{mg} / \mathrm{ml}$ ) (Omnipaque, GE Healthcare) was injected into the internal carotid artery (ICA) over 2 seconds by a power contrast injector (Medrad, Bayer HealthCare). The power contrast injector was synchronized to a fluoroscopy angiographic machine with a 1.2-second delay in the contrast injection. A biplane neuroangiography suite (Artis zee, Siemens Medical Solutions) was used to capture DSA images at a rate of 4 frames/sec in standard anterior-posterior, lateral, and oblique transorbital projections. Digitally subtracted images were saved to the Picture Archiving and Communicating System. In addition, the entire unedited angiogram was archived on a separate DVD in Digital Imaging and Communications in Medicine (DICOM) format.

\section{Estimation of TTs}

To interpret relative blood flow within ROIs in the intracranial circulation, we developed a custom MATLABbased software code (MathWorks). Representative consecutive DICOM images from DSA runs were loaded to a separate personal computer and analyzed for time-intensity using this novel method. The MATLAB-based software analyzed the image intensity throughout the entire angiogram and identifies various intensity plots including the maximum gray intensity in consecutive DICOM images. Various ROIs were selected throughout the major cerebral vessels: ICA, segments of anterior cerebral artery $\left(\mathrm{A}_{1}\right.$ and $\left.A_{2}\right)$, segments of the middle cerebral artery $\left(M_{1}\right.$ and $\mathrm{M}_{2}$ ). The ROI includes 3 to 4 pixels, and the average TT over individual ROIs was calculated. The time-intensity plots were analyzed at the selected ROI with regard to the image intensity over the angiography run-time. The timeintensity plot was divided into 3 components, and estimated TTs were defined as follows (Fig. 1): TTP 0\%-100\% $\left(\mathrm{TTP}_{0-100}\right)$ was defined as the time needed for the contrast density profile to reach maximum level (time to peak; TTP) from the time of the injection; TTP 25\%-100\% $\left(\mathrm{TTP}_{25-100}\right)$ was defined as the time needed for the contrast density profile to reach maximum (100\%) from $25 \%$ of the maximum density, and $\mathrm{TT}_{100-10}$ was the time needed for the contrast density to reach $10 \%$ from its maximum value (100\%) (Fig. 1). These 3 different TTs represent TTs during the early portion of the contrast passage in the intracranial circulation $\left(\mathrm{TTP}_{0-100}\right.$ and $\left.\mathrm{TTP}_{25-100}\right)$ as well as the late phase of the contrast curve $\left(\mathrm{TT}_{100-10}\right)$ as it transverses the intracranial circulation. Only data from the anterior circulation TTs (right and left hemispheres) were collected; no posterior circulation data were collected so as to avoid heterogeneity of the data in this manuscript (Fig. 2).

\section{Statistical Analysis}

Demographic variables were compared between Group A (Hunt and Hess Grade I-II), Group B (Hunt and Hess Grade III-V), and the control group. Patients with an altered level of consciousness (Hunt and Hess Grade III$\mathrm{V})$ were grouped together in an attempt to determine whether delayed TTs represent a common finding related to the neurological examination in DSA analysis. The

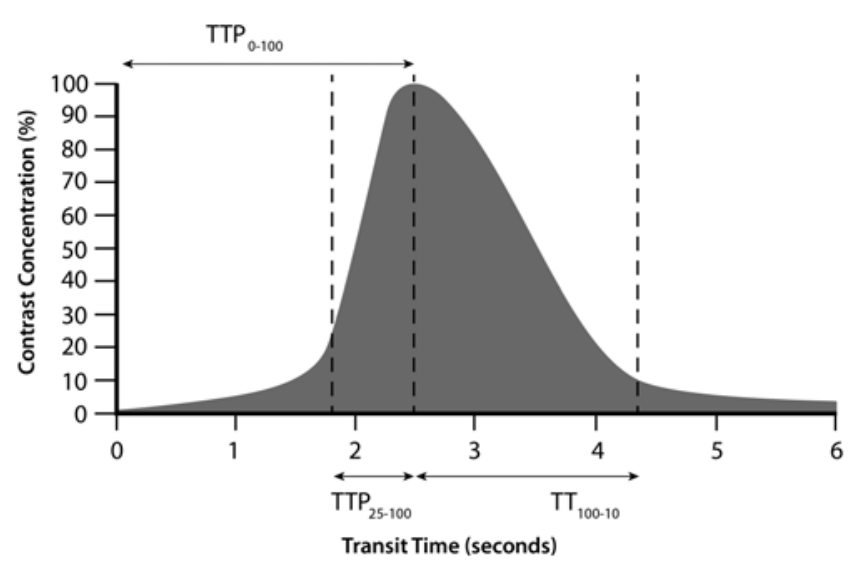

FIG. 1. Graph showing the time-contrast density profile and the portions of the curve representing the various TTs. 

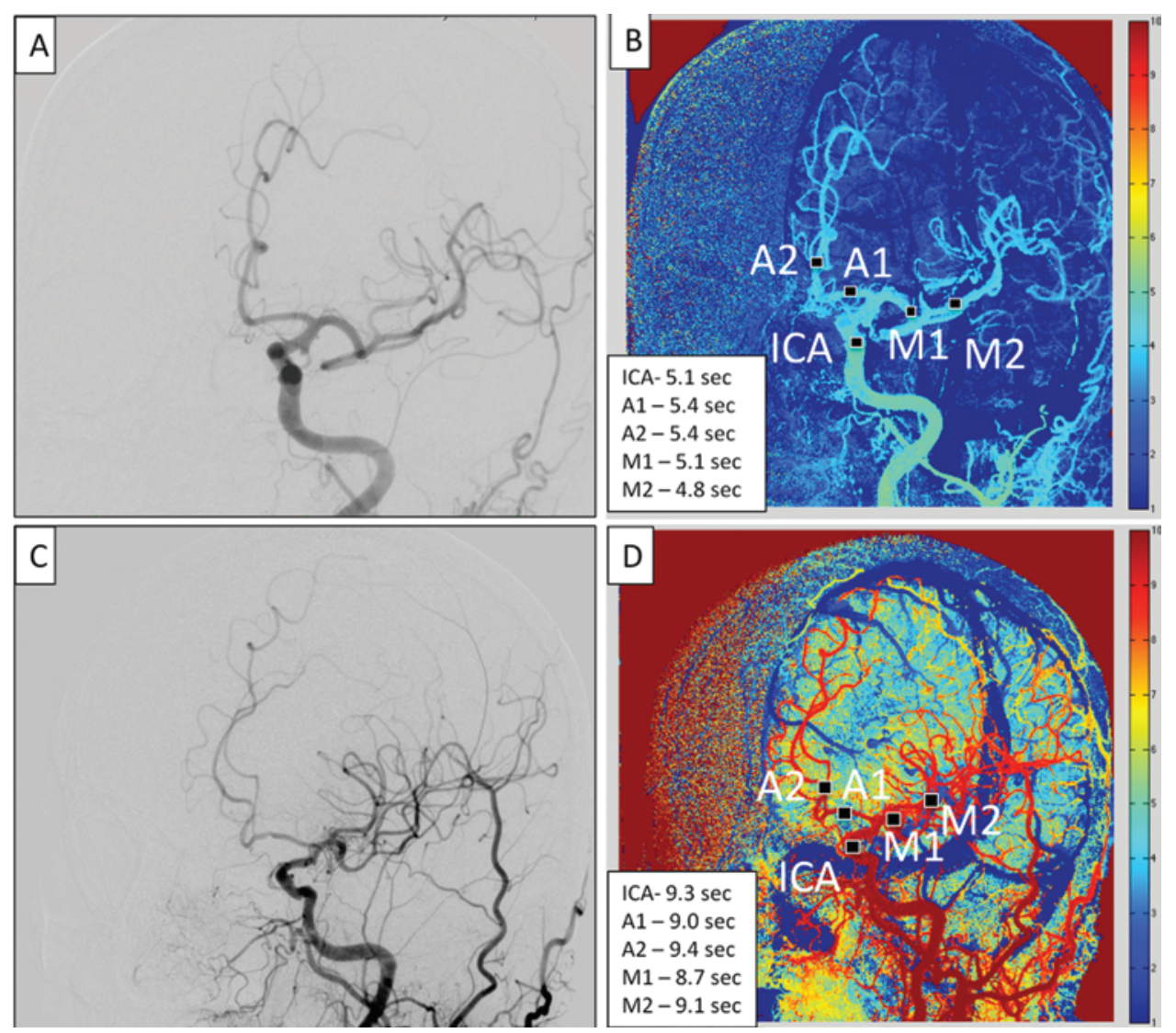

FIG. 2. Cerebral angiograms obtained in representative patients from Groups $A$ and $B$. A: Diagnostic cerebral angiogram of a patient from Group A (Hunt and Hess Grade I). B: Corresponding reconstructed color-coded time-density TT 100-10 of $(\mathrm{A})$ showing corresponding ROls $\left(A_{1}, A_{2}, M_{1}, M_{2}\right)$. C: Diagnostic cerebral angiogram of a patient from Group $B$ (Hunt and Hess Grade $\mathrm{V})$. D: Corresponding reconstructed color-coded time-density $\mathrm{TT}_{100-10}$ of $(\mathrm{B})$ showing corresponding ROls. Figure is available in color online only.

clinical data were compared between the 2 independent groups (Group A and Group B). The $\mathrm{TTP}_{0-100}, \mathrm{TTP}_{25-100}$, and $\mathrm{TT}_{100-10}$ for the corresponding ROIs were compared between Group A and Group B; $\mathrm{TT}_{100-10}$ were compared between aSAH patients groups and the control group, as well as to the control group. A Student t-test was used for analysis between Group A and Group B, and an ANOVA test was used to compare between the 3 groups. A p value $<0.05$ was defined as a significant difference. All TT analysis was performed for all ROIs (ICA, $\mathrm{M}_{1}, \mathrm{M}_{2}, \mathrm{~A}_{1}$, and $A_{2}$ ). The TT values for different ROIs were correlated with each other by using scatter plots and calculation of the coefficient of determination $\left(\mathrm{R}^{2}\right)$. The statistical analysis was performed using IBM SPSS Statistics for Macintosh, Version 21.0.

\section{Results}

There was no difference in demographic factors between the 3 groups: Group A $(n=10)$, Group B $(n=20)$, and the control group $(n=10)$. All patients with EVD catheters had a normal ICP documented during DSA (Table 1). Factors that might influence the baseline cerebral perfusion including age, sex, hypertension, diabetes, and smoking were comparable between the groups. General anesthesia was equally used during cerebral angiography between aSAH groups. Outcomes at 6 months after patient discharge were significantly worse based on mRS and GOS in Group B patients (Table 1).

Analysis of the $\mathrm{TTP}_{0-100}$ time-density plot between different representative ROIs of ICA, $\mathrm{M}_{1}, \mathrm{M}_{2}, \mathrm{~A}_{1}$, and $\mathrm{A}_{2}$ of the same patients showed the weakest correlation between those ROIs ( $\mathrm{R}^{2}$ varied between 0.434-0.841) (Fig. 3A). The correlation between different ROIs was stronger in the $\mathrm{TTP}_{25-100}\left(\mathrm{R}^{2}\right.$ varied between 0.656-0.931) (Fig. 3B). The strongest correlations were observed between the representative ROIs in the $\mathrm{TT}_{100-10}$ time-intensity plot $\left(\mathrm{R}^{2}\right.$ varied between 0.893-0.955) (Fig. 3C). The weak correlation in $\mathrm{TTP}_{0-100}$ may represent an inherent problem related to the fact that this portion of the time curve is the earliest and the most sensitive to the induced hemodynamic changes caused by the contrast power injector and to the limited frame rate of the angiography hardware. This artifact is less evident in the last portion of the time-intensity plot $\left(\mathrm{TT}_{100-10}\right)$. The correlation between different ROIs in $\mathrm{TT}_{100-}$ ${ }_{10}$ is very close to 1 , indicating that the TTs for each corresponding ROI are almost identical to the other regions, and might indicate comparable perfusion in different regions of the brain. This also indicates that the most sensitive TT is $\mathrm{TT}_{100-10}$ since it is least affected by the hemodynamic changes induced by the contrast injector (Fig. 3D). 
TABLE 1. Patient demographic and clinical data*

\begin{tabular}{lcccc}
\hline \multicolumn{1}{c}{ Characteristic } & Group A† $(\mathrm{n}=10)$ & Group B $\neq(\mathrm{n}=20)$ & Control Group $(\mathrm{n}=10)$ & $\mathrm{p}$ Value \\
\hline Female & $5(50)$ & $10(50)$ & $7(70)$ & 0.545 \\
\hline Mean age in yrs \pm SD & $55.5 \pm 14.7$ & $57.7 \pm 9.6$ & $51.2 \pm 10.1$ & 0.690 \\
\hline Diabetes & $1(10)$ & $2(10)$ & $1(10)$ & 0.112 \\
\hline Smoker & $6(60)$ & $11(55)$ & $4(40)$ & 0.637 \\
\hline Hypertension & $4(40)$ & $10(50)$ & $3(30)$ & 0.114 \\
\hline Hyperlipidemia & $3(30)$ & $5(25)$ & $4(40)$ & 0.621 \\
\hline EVD placement & 0 & 17 & $\mathrm{NA}$ & $\mathrm{NA}$ \\
\hline GA for diagnostic angiography & $8(80)$ & $18(90)$ & $\mathrm{NA}$ & 0.407 \\
\hline LVEF <50\% on admission & 1 & 1 & $\mathrm{NA}$ & 0.483 \\
\hline mRS score 0-2 at 6 mos & $9(90)$ & $7(35)$ & & 0.004 \\
\hline
\end{tabular}

$\mathrm{GA}=$ general anesthesia; $\mathrm{LVEF}=$ left ventricle ejection fraction; $\mathrm{NA}=$ not applicable.

* Values are $\mathrm{n}(\%)$ except where indicated. Bold type indicates statistical significance.

$\dagger$ Hunt and Hess Grade I-II.

$\ddagger$ Hunt and Hess Grade III-V.
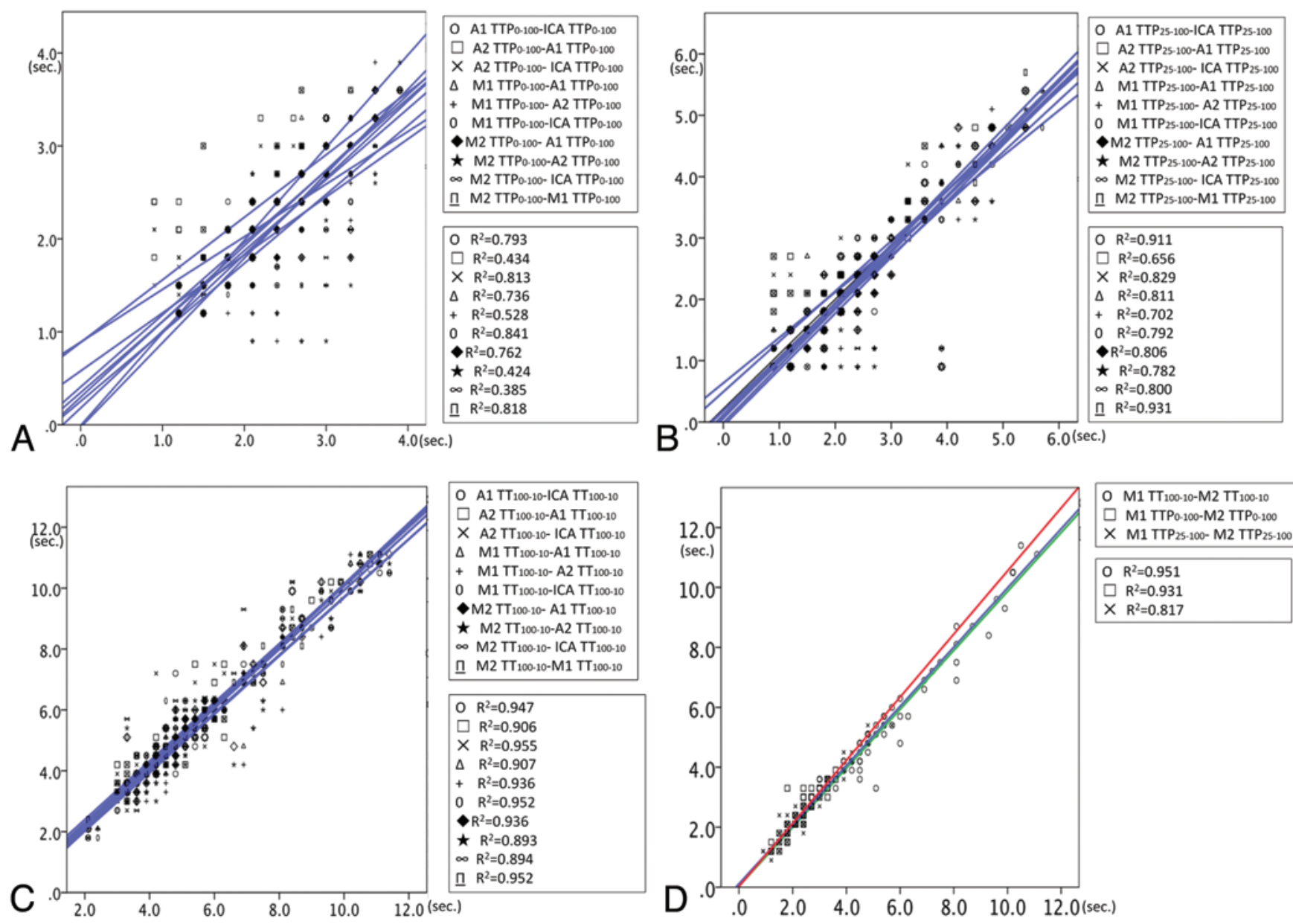

FIG. 3. Scatter plots showing the TTPs and TTs across different ROls and the corresponding correlation coefficients. A: Scatter

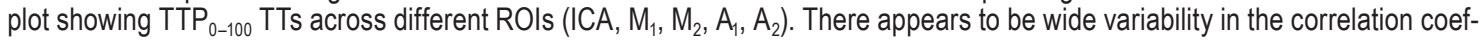
ficients between different ROIs. B: Scatter plot showing TTP $25-100$ TTs between different ROls. Higher correlation coefficients than those of TTP ${ }_{0-100}$ are evident. C: Scatter plot showing TT 100-10 $^{25-100}$ Ts between different ROls. Higher correlation coefficients than those of TTP $\mathrm{T}_{0-100}$ and TTP $25-100$ are evident. D: Scatter plot comparing multiple TTs (TTP $0-100, \mathrm{TTP}_{25-100}$, and TT $\left.100-10\right)$ across $\mathrm{M}_{1}$ and $M_{2}$ segments. For the same regions, the correlation coefficient is highest for $\operatorname{TT}_{100-10}\left(R^{2}=0.951\right)$ and weakest for TTP $\operatorname{TP}_{0-100}\left(R^{2}\right.$ $=0.817$ ). Figure is available in color online only. 
There was a statistically significant difference in TTs in the ROI $\mathrm{M}_{1}: \mathrm{M}_{1}-\mathrm{TTP}_{0-100}$ between Groups A and B (1.98 vs 2.43 seconds, $\mathrm{p}=0.005), \mathrm{M}_{1}-\mathrm{TTP}_{25-100}(1.78$ vs 2.7 seconds, $\mathrm{p}=0.003$ ), and in $\mathrm{M}_{1}-\mathrm{TT}_{100-10}$ (4.68 vs 6.27 seconds, $\mathrm{p}=$ 0.012 ), respectively (Fig. 4 left). Similar differences were observed in the ROI $\mathrm{A}_{1}: \mathrm{A}_{1}-\mathrm{TTP}_{0-100}(1.84$ vs 2.18 seconds, $\mathrm{p}=0.001), \mathrm{A}_{1}-\mathrm{TTP}_{25-100}(1.63$ vs 2.27 seconds, $\mathrm{p}=0.001)$, and in $\mathrm{A}_{1}-\mathrm{TT}_{100-10}$ (4.24 vs 5.12 seconds, $\left.\mathrm{p}=0.0015\right)$, respectively (Fig. 4 right), and for the ROI $\mathrm{M}_{2}: \mathrm{M}_{2}-\mathrm{TTP}_{0-100}$ (2.03 vs 2.64 seconds, $\mathrm{p}=0.001), \mathrm{M}_{2}-\mathrm{TTP}_{25-100}(1.83$ vs 2.8 seconds, $\mathrm{p}=0.001$ ), and in $\mathrm{M}_{2}-\mathrm{TT}_{100-10}$ (4.68 vs 6.2 seconds, $p=0.012$ ). A statistically significant difference was observed in $\mathrm{TT}_{100-10}$ between Group B and the control group, with significant TT delays in patients with aSAH. The $\mathrm{TT}_{100-10}$ value in Group A (patients with Hunt and Hess Grade I-II) was shorter in all ROIs, without a significant difference compared with the control group. Results were unchanged by exclusion of patients without an EVD at the time of angiography. No significant difference was found between Groups A and B in estimated left ventricle ejection fraction percentage obtained within 24 hours after cerebral angiogram.

\section{Discussion}

In this study, we report a new algorithm of DSA image processing that is simple to incorporate, inexpensive, and available in angiography suites for real-time analysis. The results demonstrate strong correlations between all angiographic TTs and patient clinical presentation, and significant TT delays in patients with poor-grade aSAH (Hunt and Hess Grade III-V).

Postprocessing software similar to that used for our TTP $_{0-100}$ analysis has been developed by Siemens (iFLOW), Phillips (Allura Xper), and GE Healthcare (AngioViz), and is currently commercially available. To date, the successful use of this technique was reported following endovascular treatment of carotid cavernous fistulas, ${ }^{27}$ carotid stenosis, ${ }^{26}$ and cerebral vasospasm. ${ }^{25}$ The main limitation of the commercially available postprocessing software is its reliance on the TTP portion of the DSA curve. As we have shown, this part of the curve is the least sensitive of the 3 TTs that we evaluated. It is believed that the early TT is heavily affected by the hemodynamic artifact from the contrast power injector and limited images acquisition speed, which alters the DSA TT in the early phase of the DSA curve. Our analysis has shown that the $\mathrm{TT}_{100-10}$ is much less sensitive than TTP $_{0-100}$ to the above-mentioned factors.

Early studies on flow analysis with DSA ${ }^{18}$ showed that time-intensity curve geometry depends on the flow, vessel size, amount of iodine injected, and framing rate. It is not affected by volume, concentration, or rate of injection..$^{18}$ This is true if the area under the curve is used as a surrogate of the flow in the ROI. We evaluated only the TT (not the area under the curve) in our method; thus, the vessel size and amount of iodine injected did not affect our results. The time-intensity curve in cerebral angiography is not symmetric but rather skewed to the right, with a longer negative slope run-time (longer $\mathrm{TT}_{100-0}$ as compared with $\left.\mathrm{TT}_{0-100}\right)$. Therefore, changes in the flow are easier to detect within the negative slope run-time. This observation was made using DSA on different flow rates in a basic plastic model. ${ }^{17}$

The Hunt and Hess scale was introduced in 1968 with the initial purpose of assessing the surgical risk in patients with aSAH based on patient clinical status on presentation prior to surgery. ${ }^{20}$ Several studies showed high correlation between Hunt and Hess scores and clinical outcomes, with higher grades corresponding to increasingly poor prognosis. ${ }^{729} \mathrm{~A}$ patient's clinical presentation after aSAH is a reflection of the global CBF. In aSAH cases, the $\mathrm{CBF}$ is considerably affected by a combination of factors including brain exposure to blood product, elevated ICP, mechanical distortion of the blood vessels, and impaired cerebral vessel autoregulation. ${ }^{4,5,8,34}$ Previous as-
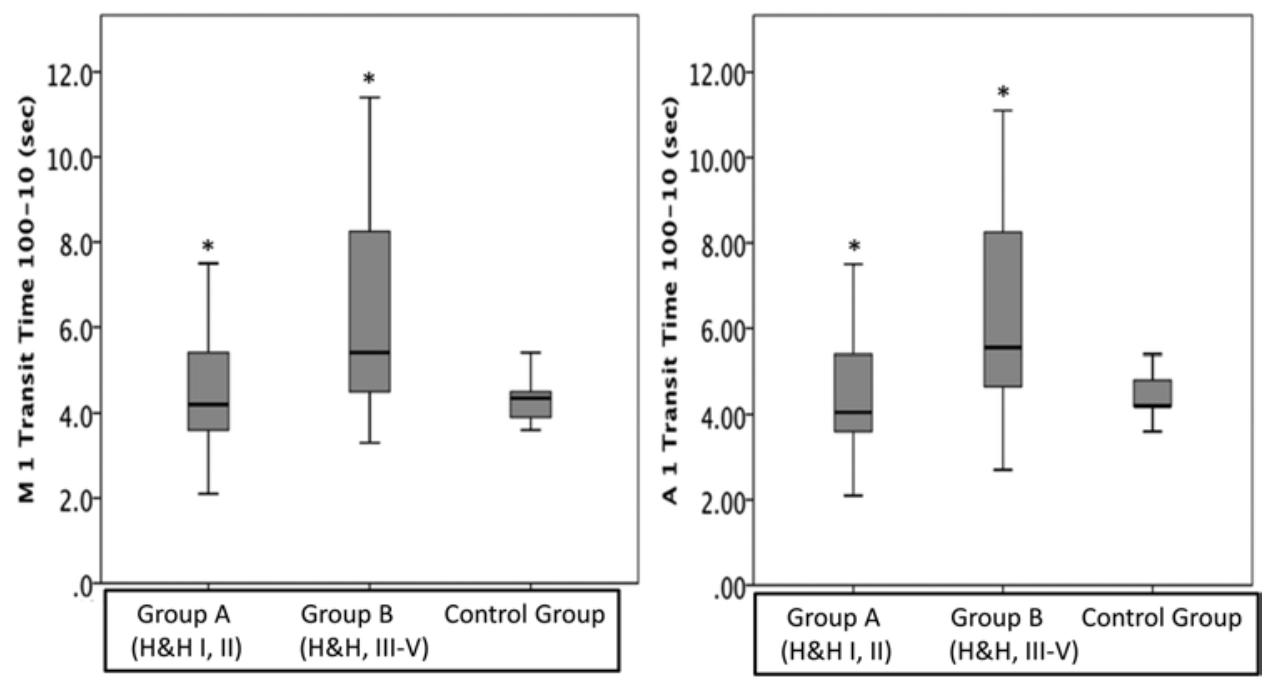

FIG. 4. Box plots comparing differences between groups in $T T_{100-10}$ for ROls $M_{1}$ and $A_{1}$. Left: Box plot comparing the $T T_{100-10} R O I$ over $\mathrm{M}_{1}$ between Group A, Group B, and the control group. Right: Box plot comparing the $\mathrm{TT}_{100-10} \mathrm{ROI}$ over $\mathrm{A}_{1}$ between Group $\mathrm{A}$, Group B, and the control group. For each of the box plots, asterisks represent a statistically significant difference between Groups $A$ and $B$ but not between Group $A$ and the control group. The boxes represent the interquartile range, horizontal rule the median, and the whiskers the minimum and maximum values. $\mathrm{H} \& \mathrm{H}=$ Hunt and Hess Grade. 
sumptions about the intact $\mathrm{CBF}$ autoregulation during the early period of $\mathrm{aSAH}^{38}$ have been challenged by several animal studies showing CBF impairment even in the early phase after ictus. ${ }^{4,12,32}$ Clinical studies with PET scans have demonstrated impairment of CBF in early aSAH in the absence of radiographic vasospasm, along with decreases in metabolic rate of oxygen..$^{10,24}$ MR images performed early after ictus (within 0-3 days) have shown an approximately $60 \%$ incidence of diffusion-weighted imaging (DWI)detected lesions. The presence of any early DWI/apparent diffusion coefficient lesion and increasing lesion volume were associated with a worse $\mathrm{H} \& \mathrm{H}$ grade and correlated with future poor neurological outcomes. ${ }^{14}$ The mechanism of ischemic infarcts in those patients is thought to be related to the early development of microcirculatory vasoconstriction $^{5}$ that leads to hypoperfusion, oxidative cell injury, and subsequent cell death. ${ }^{30}$ The vasoconstriction phenomenon seems to be independent of elevated ICP, and it is accompanied by considerable CBF decreases. ${ }^{5}$

Our data are in line with the abovementioned observations: TT delays were not associated with ICP status nor related to general anesthesia per se, nor related to early myocardial stunning with low left ventricle contraction. Therefore, the determination of the relative CBF status by measuring angiographic TT in the angiography suite could have prognostic value in patients with aSAH and provides further insights into the pathophysiology of cerebral injury following aSAH.

\section{Conclusions}

The DSA TTs showed significant correlation with Hunt and Hess grades. Patients with altered mental status (Hunt and Hess Grades III-V) are found to have considerable DSA TT delays in comparison with patients with minimal clinical symptoms (Hunt and Hess Grades I-II) and patients without aneurysm rupture. The TT appears to be independent of general anesthesia and increased ICP and may be an indicator of decreased CBF in patients with aSAH. This method may serve as an indirect technique available in the angiography suite for assessing relative $\mathrm{CBF}$ changes.

\section{Acknowledgments}

We would like to thank Dr. Daniel Bailey for his kind advice and editing of the manuscript, Mr. Mananga D. Mutombo for his assistance with the data analysis, and Miss Christa Wellman for the graph.

\section{References}

1. Amin-Hanjani S, Alaraj A, Calderon-Arnulphi M, Aletich VA, Thulborn KR, Charbel FT: Detection of intracranial instent restenosis using quantitative magnetic resonance angiography. Stroke 41:2534-2538, 2010

2. Amin-Hanjani S, Du X, Zhao M, Walsh K, Malisch TW, Charbel FT: Use of quantitative magnetic resonance angiography to stratify stroke risk in symptomatic verteb robasilar disease. Stroke 36:1140-1145, 2005

3. Amin-Hanjani S, Rose-Finnell L, Richardson D, Ruland S, Pandey D, Thulborn KR, et al: Vertebrobasilar Flow Evaluation and Risk of Transient Ischaemic Attack and Stroke study
(VERiTAS): rationale and design. Int J Stroke 5:499-505, 2010

4. Bederson JB, Germano IM, Guarino L: Cortical blood flow and cerebral perfusion pressure in a new noncraniotomy model of subarachnoid hemorrhage in the rat. Stroke 26:1086-1092, 1995

5. Bederson JB, Levy AL, Ding WH, Kahn R, DiPerna CA, Jenkins AL III, et al: Acute vasoconstriction after subarachnoid hemorrhage. Neurosurgery 42:352-362, 1998

6. Binaghi S, Colleoni ML, Maeder P, Uské A, Regli L, Dehdashti AR, et al: CT angiography and perfusion CT in cerebral vasospasm after subarachnoid hemorrhage. AJNR Am J Neuroradiol 28:750-758, 2007

7. Bonilha L, Marques EL, Carelli EF, Fernandes YB, Cardoso AC, Maldaum MV, et al: Risk factors and outcome in 100 patients with aneurysmal subarachnoid hemorrhage. Arq Neuropsiquiatr 59:676-680, 2001

8. Cahill J, Calvert JW, Zhang JH: Mechanisms of early brain injury after subarachnoid hemorrhage. J Cereb Blood Flow Metab 26:1341-1353, 2006 (Erratum in J Cereb Blood Flow Metab 26:1463, 2006)

9. Calderon-Arnulphi M, Amin-Hanjani S, Alaraj A, Zhao M, Du X, Ruland S, et al: In vivo evaluation of quantitative MR angiography in a canine carotid artery stenosis model. AJNR Am J Neuroradiol 32:1552-1559, 2011

10. Carpenter DA, Grubb RL Jr, Tempel LW, Powers WJ: Cerebral oxygen metabolism after aneurysmal subarachnoid hemorrhage. J Cereb Blood Flow Metab 11:837-844, 1991

11. Cenic A, Nabavi DG, Craen RA, Gelb AW, Lee TY: A CT method to measure hemodynamics in brain tumors: validation and application of cerebral blood flow maps. AJNR Am J Neuroradiol 21:462-470, 2000

12. Delgado TJ, Brismar J, Svendgaard NA: Subarachnoid haemorrhage in the rat: angiography and fluorescence microscopy of the major cerebral arteries. Stroke 16:595-602, 1985

13. Esfahani D, Stevenson M, Moss H, Amin-Hanjani S, Aletich $\mathrm{V}$, Charbel F, et al: Quantitative MRA is correlated with intravascular pressures before and after venous sinus stenting: implications for treatment and monitoring. J Neurointerv Surg 6 (Suppl 1):A6-A7, 2014 (Abstract)

14. Frontera JA, Ahmed W, Zach V, Jovine M, Tanenbaum L, Sehba F, et al: Acute ischaemia after subarachnoid haemorrhage, relationship with early brain injury and impact on outcome: a prospective quantitative MRI study. J Neurol Neurosurg Psychiatry 86:71-78, 2015

15. Gould IG, Marinnan T, Chojecki M, Qader M, Henry B, Pervais M, et al: Hemodynamics of cerebral micro vasculature, in Karimi IA, Srinivasan R (eds): Proceedings of the 11th International Symposium on Process Systems Engineering. Amsterdam: Elsevier, 2012, pp 1727-1731

16. Grubb RL Jr, Raichle ME, Eichling JO, Gado MH: Effects of subarachnoid hemorrhage on cerebral blood volume, blood flow, and oxygen utilization in humans. J Neurosurg 46:446-453, 1977

17. Hesselink JR, Chang KH, Chung KJ, Abbate L: Flow analysis with digital subtraction angiography: 1 . Description of a simplified flow model. AJNR Am J Neuroradiol 7:423-426, 1986

18. Hesselink JR, Chang KH, Chung KJ, Abbate L, Goodsitt M: Flow analysis with digital subtraction angiography: 2. Acquisition and accuracy of transit-flow measurements. AJNR Am J Neuroradiol 7:427-431, 1986

19. Huang AP, Tsai JC, Kuo LT, Lee CW, Lai HS, Tsai LK, et al: Clinical application of perfusion computed tomography in neurosurgery. J Neurosurg 120:473-488, 2014

20. Hunt WE, Hess RM: Surgical risk as related to time of intervention in the repair of intracranial aneurysms. J Neurosurg 28:14-20, 1968

21. Ingall TJ, Whisnant JP, Wiebers DO, O'Fallon WM: Has 
there been a decline in subarachnoid hemorrhage mortality? Stroke 20:718-724, 1989

22. Kanazawa R, Kato M, Ishikawa K, Eguchi T, Teramoto A: Convenience of the computed tomography perfusion method for cerebral vasospasm detection after subarachnoid hemorrhage. Surg Neurol 67:604-611, 2007

23. Kassell NF, Torner JC, Jane JA, Haley EC Jr, Adams HP: The International Cooperative Study on the Timing of Aneurysm Surgery. Part 2: Surgical results. J Neurosurg 73:37-47, 1990

24. Knuckey NW, Fox RA, Surveyor I, Stokes BA: Early cerebral blood flow and computerized tomography in predicting ischemia after cerebral aneurysm rupture. J Neurosurg 62:850-855, 1985

25. Levitt MR, Morton RP, Haynor DR, Cohen W, Ghodke BV, Hallam DK, et al: Angiographic perfusion imaging: real-time assessment of endovascular treatment for cerebral vasospasm. J Neuroimaging 24:387-392, 2014

26. Lin CJ, Hung SC, Guo WY, Chang FC, Luo CB, Beilner J, et al: Monitoring peri-therapeutic cerebral circulation time: a feasibility study using color-coded quantitative DSA in patients with steno-occlusive arterial disease. AJNR Am J Neuroradiol 33:1685-1690, 2012

27. Lin CJ, Luo CB, Hung SC, Guo WY, Chang FC, Beilner J, et al: Application of color-coded digital subtraction angiography in treatment of indirect carotid-cavernous fistulas: initial experience. J Chin Med Assoc 76:218-224, 2013

28. Linninger AA, Gould IG, Marinnan T, Hsu CY, Chojecki M, Alaraj A: Cerebral microcirculation and oxygen tension in the human secondary cortex. Ann Biomed Eng 41:22642284,2013

29. Oshiro EM, Walter KA, Piantadosi S, Witham TF, Tamargo RJ: A new subarachnoid hemorrhage grading system based on the Glasgow Coma Scale: a comparison with the Hunt and Hess and World Federation of Neurological Surgeons Scales in a clinical series. Neurosurgery 41:140-148, 1997

30. Ostrowski RP, Colohan AR, Zhang JH: Neuroprotective effect of hyperbaric oxygen in a rat model of subarachnoid hemorrhage. Acta Neurochir Suppl 96:188-193, 2006

31. Proust F, Hannequin D, Langlois O, Freger P, Creissard P: Causes of morbidity and mortality after ruptured aneurysm surgery in a series of 230 patients. The importance of control angiography. Stroke 26:1553-1557, 1995

32. Rasmussen G, Hauerberg J, Waldemar G, Gjerris F, Juhler M: Cerebral blood flow autoregulation in experimental subarachnoid haemorrhage in rat. Acta Neurochir (Wien) 119:128-133, 1992

33. Ruland S, Ahmed A, Thomas K, Zhao M, Amin-Hanjani S,
Du X, et al: Leptomeningeal collateral volume flow assessed by quantitative magnetic resonance angiography in largevessel cerebrovascular disease. J Neuroimaging 19:27-30, 2009

34. Schmieder K, Jarus-Dziedzic K, Wronski J, Harders A: CO2 reactivity in patients after subarachnoid haemorrhage. Acta Neurochir (Wien) 139:1038-1041, 1997

35. Shakur SF, Hrbac T, Alaraj A, Du X, Aletich VA, Charbel FT, et al: Effects of extracranial carotid stenosis on intracranial blood flow. Stroke 45:3427-3429, 2014

36. Voldby B, Enevoldsen EM, Jensen FT: Regional CBF, intraventricular pressure, and cerebral metabolism in patients with ruptured intracranial aneurysms. J Neurosurg 62:48-58, 1985

37. Yoshikai S, Nagata S, Ohara S, Yuhi F, Sakata S, Matsuno $\mathrm{H}$ : [A retrospective analysis of the outcomes of patients with aneurysmal subarachnoid hemorrhages: a focus on the prognostic factors.] No Shinkei Geka 24:733-738, 1996 (Jpn)

38. Yundt KD, Grubb RL Jr, Diringer MN, Powers WJ: Autoregulatory vasodilation of parenchymal vessels is impaired during cerebral vasospasm. J Cereb Blood Flow Metab 18:419-424, 1998

\section{Disclosure}

Dr. Charbel reports direct stock ownership in Vassol Inc.

\section{Author Contributions}

Conception and design: Alaraj. Acquisition of data: Ivanov. Analysis and interpretation of data: Ivanov, Linninger, Hsu. Drafting the article: Ivanov, Hsu. Critically revising the article: Alaraj, Ivanov, Linninger, Amin-Hanjani, Aletich, Charbel. Reviewed submitted version of manuscript: Alaraj, Ivanov, Linninger, Amin-Hanjani, Aletich, Charbel. Approved the final version of the manuscript on behalf of all authors: Alaraj. Statistical analysis: Ivanov. Study supervision: Alaraj, Linninger.

\section{Supplemental Information}

\section{Previous Presentation}

Portions of this work were presented in the form of a poster at the CNS Annual Meeting (October 18-22, 2014, Boston, MA).

\section{Correspondence}

Ali Alaraj, Department of Neurosurgery (MC-799), Neuropsychiatric Institute, University of Illinois at Chicago, 912 S. Wood St., Chicago, IL 60612-7329. email: alaraj@uic.edu. 